\title{
In situ monitoring for ground truthing paste backfill designs
}

\author{
M.W. Grabinsky University of Toronto, Canada
}

\begin{abstract}
Optimised geomechanical design of cemented paste backfill systems requires feedback on the actual field performance of paste fills and their barricades during filling, subsequent curing, and exposure to ongoing mining activities. A comprehensive monitoring strategy is described and its application is demonstrated for five stopes at three different mining operations. Important information is revealed about several poorly understood phenomena including stress arching within the fill mass, barricade pressure reduction with increasing setback from the stope, temperature induced stresses, and liquefaction potential of paste fill due to production blasting and rockbursts. Consideration is given to optimised monitoring procedures that other engineers could use to investigate similar phenomena at their mines.
\end{abstract}

\section{Introduction}

Cemented paste backfill has gained wider acceptance in the mining industry and the number of paste backfill operations has expanded significantly in recent years, primarily due to the increasing reliability of paste production and transport technologies, as well as the rapid delivery rates of paste relative to other backfill methods, and also due to the fact that mine tailings - which have traditionally been considered a waste product that must otherwise be managed in engineered disposal facilities - are instead turned into a valueadded product that provides regional ground support.

The early days of paste backfill research and development focussed on the methods used to produce and transport paste; much less effort was devoted to understanding how the paste performed after it left the end of the pipe and was deposited into the stope. Currently, predominantly empirical techniques (or 'rules of thumb') are used to make many critical geomechanical design decisions for paste backfill systems, including required binder content, backfilling strategies in terms of a continuous versus multi-stage pour, selecting fill barricade types and their dimensions and construction details, maximum rates of fill rise, assessing susceptibility of paste to failure (including liquefaction) due to self weight loading or dynamic loads induced by rockbursts or blasting, and predicting long-term paste performance during prolonged mining activity.

Optimizing paste backfill systems in support of enhanced economic and environmental sustainability of a mining operation requires engineers to move beyond the traditional empirical techniques, and to make better use of rational design tools that appropriately consider the paste's material properties, stope geometry, and the loads imposed by the paste's self weight and the surrounding mining activities. Research in support of rational design has tended to focus on isolated aspects of analysis ( $\mathrm{Li}$ and Aubertin, 2009; Mitchell et al., 1982; Helinski et al., 2008) and material behaviour (Helinski et al., 2007; Simms and Grabinsky, 2009; Yilmaz et al., 2009). However, it has yet to be demonstrated how these research efforts can be incorporated into the actual design of mining operations. To do that, extensive field monitoring programs are required to quantify the paste backfill's field performance and to verify the suitability of the design procedures used.

In November 2006, an intensive research effort was initiated to develop a comprehensive instrumentation strategy for cemented paste backfill, and to demonstrate the usefulness of this system in operating mines. To date, five different stopes and their fill barricades have been monitored during filling and subsequent mining, and monitoring continues in some of these stopes where feasible. The purposes of this paper are to i) provide an overview of the geometry of the stopes and the instrumentation strategies employed, ii) describe the nature of expected results and show selected field results that highlight the usefulness of the information obtained, iii) consider some details of the instrumentation design and installation, and iv) consider developments that will help make future instrumentation programs practical for other mining operations. 


\section{Description of monitored stopes}

The stope sizes, volumes, and fill rise rates considered in the research study are given in Table 1, and their typical geometries are illustrated in Figure 1. All of the fill barricades were constructed of steel reinforced shotcrete, with construction details and dimensions based on the individual mines' protocols. The barricades ranged from 5-6 m high, and 5-10 m wide. The binder designs and filling strategies employed for the test stopes are given in Table 2.

Table 1 Dimensions, volumes, and fill rise rates of stopes studied

\begin{tabular}{llllllll}
\hline & & \multicolumn{3}{c}{ Dimensions } & \multicolumn{3}{c}{ Rise Rates } \\
$\begin{array}{l}\text { Mine } \\
\text { (Stope) }\end{array}$ & $\begin{array}{l}\text { Stope } \\
\text { Type }\end{array}$ & $\begin{array}{l}\text { Height } \\
(\mathbf{m})\end{array}$ & $\begin{array}{l}\text { Strike } \\
(\mathbf{m})\end{array}$ & $\begin{array}{l}\mathbf{F W}-\mathbf{H W} \\
\mathbf{( m )}\end{array}$ & $\begin{array}{l}\text { Volume } \\
\left(\mathbf{m}^{\mathbf{3}}\right)\end{array}$ & $\begin{array}{l}\text { Mean } \\
(\mathbf{m} / \mathbf{h r})\end{array}$ & $\begin{array}{l}\text { Undercut } \\
(\mathbf{m} / \mathbf{h r})\end{array}$ \\
\hline Williams & Alimak & 150 & 30 & 5 & 10,000 & 0.75 & 0.42 \\
Kidd (67) & Long hole & 32 & 28 & 12 & 15,500 & 0.26 & 0.24 \\
Kidd (88) & Long hole & 40 & 11.5 & 18 & 10,800 & 0.50 & 0.60 \\
$\begin{array}{l}\text { Cayeli } \\
(685)\end{array}$ & Long hole & 17 & 8.5 & 25 & 3,260 & $0.22-0.25$ & $0.30-0.59$ \\
$\begin{array}{l}\text { Cayeli } \\
(715)\end{array}$ & Long hole & 15 & 8.5 & 15 & 1,215 & 0.37 & $0.23-0.49$ \\
\hline
\end{tabular}

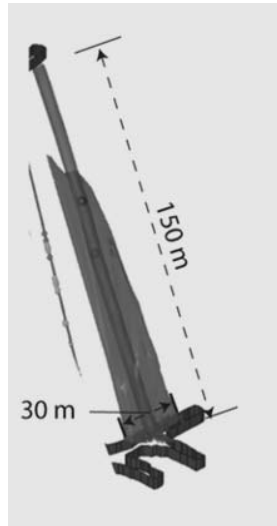

Williams

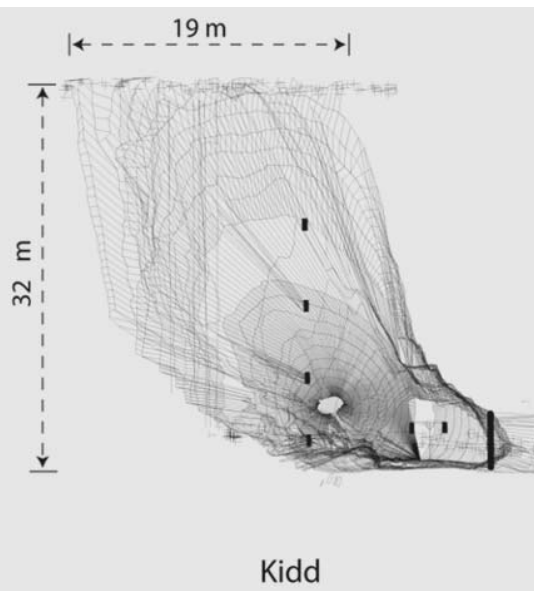

Kidd

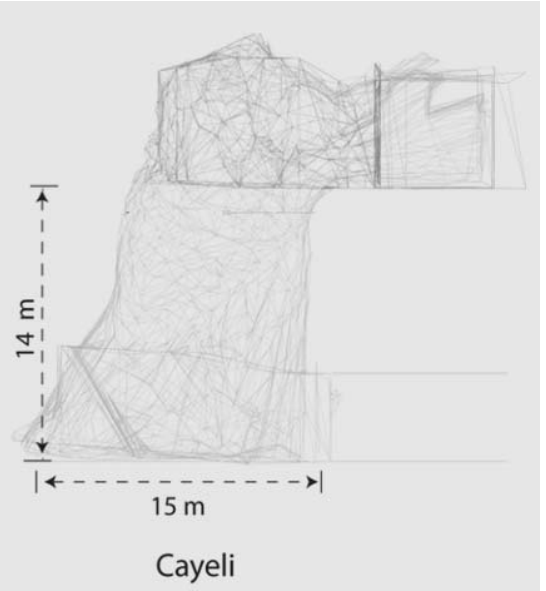

Figure 1 Typical geometries of stopes studied

Table 2 Binder designs and filling strategies for stopes studied

\begin{tabular}{|c|c|c|}
\hline Mine & Binder Design & Filling Strategy \\
\hline Williams & $\begin{array}{l}3 \% \text { 50:50 Normal Portland Cement and } \\
\text { Type C Fly Ash (NPC:CFA) }\end{array}$ & $\begin{array}{l}\text { Pour } 8 \mathrm{~m} \text { 'plug' and wait } 24 \text { hours to set; } \\
\text { resume pour for remainder of stope }\end{array}$ \\
\hline Kidd & $\begin{array}{l}55: 45 \text { alluvial sand to tailings in paste form; } \\
2.5-5.5 \% \text { binder (by combined mass of } \\
\text { solids), } 90: 10 \text { slag:NPC }\end{array}$ & $\begin{array}{l}\text { Pour 'plug' until the monitored pressures reach } \\
85 \mathrm{kPa}(12 \mathrm{psi}) \text {; wait for pressure dissipation, } \\
\text { then resume pour for remainder of stope }\end{array}$ \\
\hline Cayeli & $\begin{array}{l}6.5-8.5 \% \text { Portland Cement (manufactured } \\
\text { by Oyak Ünye Cement, Turkey) }\end{array}$ & $\begin{array}{l}\text { Pour } 8 \mathrm{~m} \text { 'plug' and wait } 3-7 \text { days; resume } \\
\text { pour for remainder of stope }\end{array}$ \\
\hline
\end{tabular}




\section{Overview of instrumentation strategy}

Several types of transducers were used at any given location to provide more complete information about the paste's behaviour and response to filling and mining activities. Details of the instrumentation will be considered in Section 6, but the general approach was to incorporate these various instruments into a cluster or cage, which was then mounted in a more robust installation cage for field application (Figure 2). Several such cages were then suspended along the height of the stope and under the brow approaching the barricades (Figure 3) using a variety of methods that will be considered subsequently in Section 7. Video cameras were used in some stopes, both within the stope to record how the paste flows behind the barricade and through the instrumentation cages, as well as at the free face of barricades to record gross deformation response to filling. The free faces of the barricades were also monitored for deformation using an array of displacement gauges.

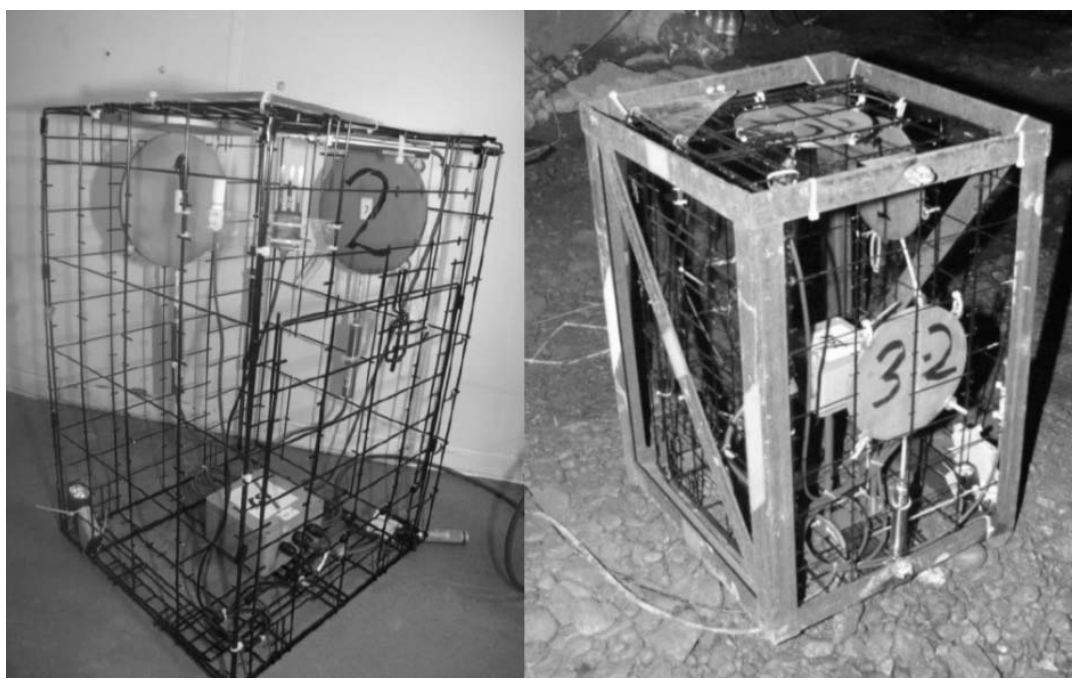

Figure 2 Instrumentation cage (left) embedded in an installation cage (right) for field application
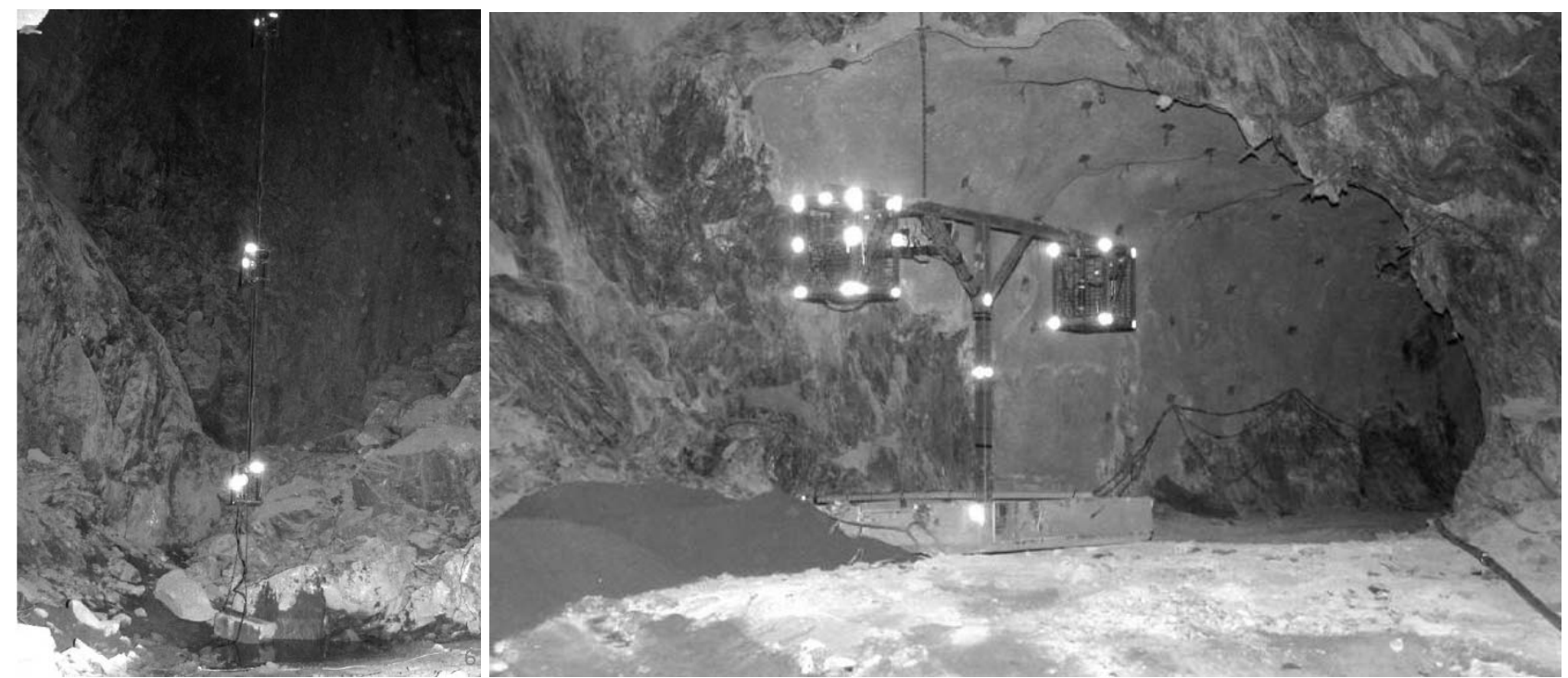

Figure 3 Installation of cages throughout the height of the stope (left) and under the brow (right)

\section{$4 \quad$ Nature of expected results}

Figure 4 presents the results of a relatively straightforward case involving a single monitoring point (i.e. instrumentation cage) within a plug fill. Time zero coincides with the start of filling, and the ambient temperature within the stope is $26^{\circ} \mathrm{C}$. The fill reaches the elevation of the various instruments within the cage 
at around 0.25 to 0.3 days, depending on the elevation of the instrument's sensing surface. Initially the total stresses are equal to the pore water pressure (i.e. the effective stresses are zero, and therefore the paste is behaving as a fluid) and the rate of pressure increase corresponds to the increasing height of overburden paste multiplied by its unit weight. Shortly after half a day the temperature increase can be seen to accelerate, corresponding to the setting of the binder. Binder hydration also consumes or otherwise involves water by a variety of mechanisms (Acker, 2004) which results in a net volume reduction of the water phase. This leads to a reduction in pore water pressure and an increase in effective stresses, which has been demonstrated in the laboratory for various pastes (Grabinsky and Simms, 2006; Helinski et al., 2007; Simms and Grabinsky, 2009). The same phenomenon can be seen in the field results in Figure 4, starting shortly after day one when pore water pressures fall below total stresses (indicating the development of effective stresses) and the horizontal stresses fall below the vertical stress, indicating the development of the initial stress state within the fill mass. What is also important to note in Figure 4 is that the vertical total stress remains consistent with expected overburden pressures up until shortly after day two. The fall off in vertical stress beyond day two suggests the development of stress arching within the fill mass, although additional results of the type in Figure 4 are required at other points to better support the arching hypothesis.

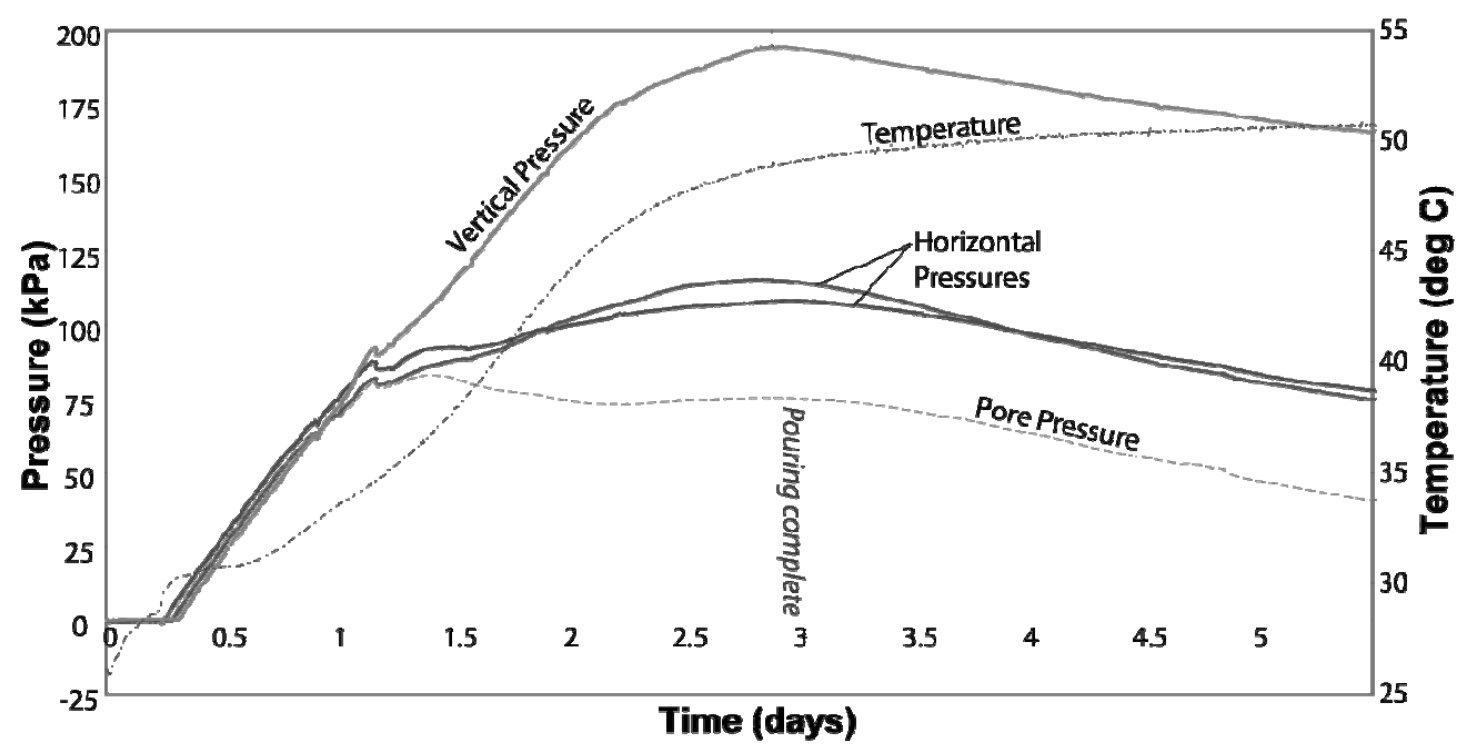

Figure 4 Example of pressure and temperature response at a single location within a plug fill

In addition to temperature changes, another good indicator of binder hydration is changes in the electrical conductivity of the fill mass. This will be discussed more fully in subsequent sections.

\section{$5 \quad$ In situ monitoring examples}

The following examples are intended to highlight some of the engineering insights that can be gained through an extensive monitoring program such as that used for the stopes monitored in the research project. It is important to note that the results are particular to the mining operations investigated, and care must be taken in attempting to extend these results to other mines. In general, instrumentation programs will be required at each mine in order to obtain the specific data required to fully optimise each operation's performance.

\subsection{Barricade performance}

Two of the primary engineering questions regarding barricades are i) what are the pressures actually acting on the barricade? And ii) what is the ultimate pressure that the barricade can withstand? Figure 5 shows the load-displacement response for a barricade where the pressures on the fill side of the barricade were measured at the quarter-height points and displacements at the free face were measured using a three row by three column monitoring array. The total pressures correspond to the expected height of fill above the respective cell, multiplied by the fill's unit weight; thus indicating that the barricade is being subjected to 
fluid loading. This fluid loading is the result of a relatively low binder content and high fill rise rate, and therefore represents one of the more severe loading scenarios for the mine. Although the barricade exhibited visible cracking, it did not fail. This input is now being used in an advanced structural analysis to better understand the nonlinear response of the barricade, and to optimise the design of future such barricades. For one of the mines participating in the research, such data and subsequent reassessment of their barricades led to increasing the allowable barricade pressure by $50 \%$, with the subsequent implication that most of their stopes can now be continuously filled rather than waiting for the 'plug' to cure. This change represents a quantifiable and important reduction in the stope cycle time, and considerable payback on their investment in the research project.

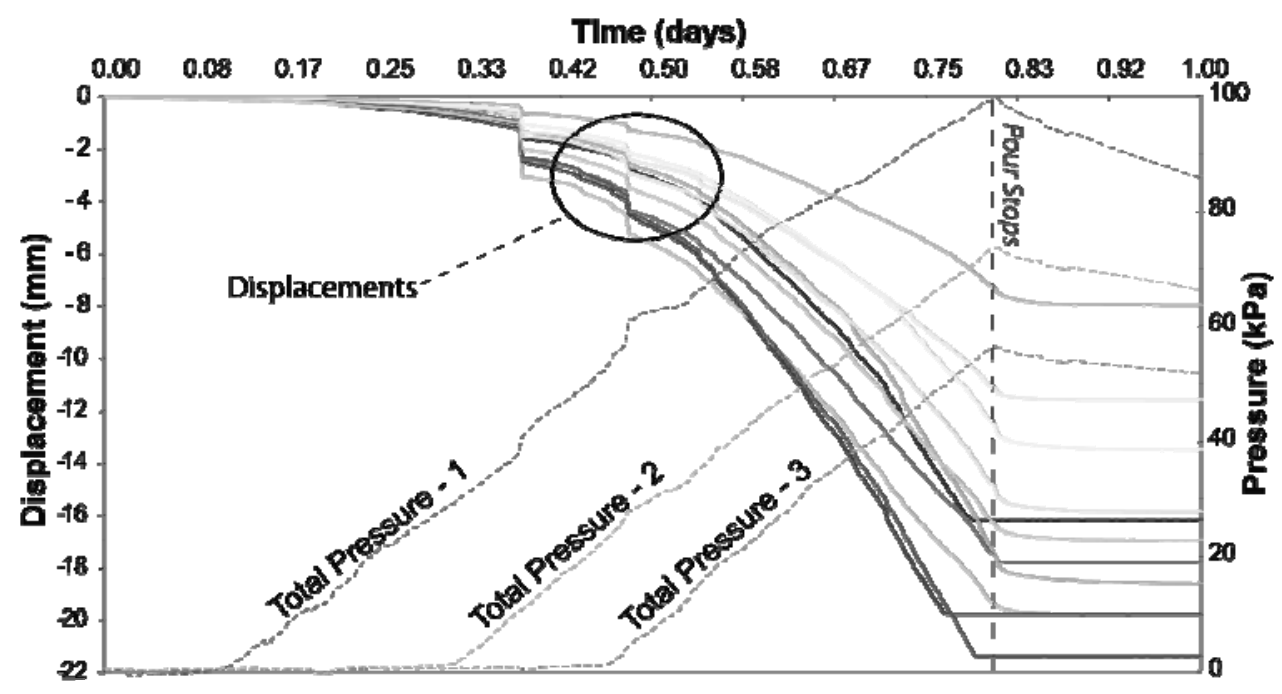

Figure 5 Example barricade load-displacement results. Note: the displacement range was exceeded for several sensors causing data to flat line before the end of pouring

\subsection{Stress arching}

The phenomenon of stress arching in granular materials has been used to explain a variety of observed behaviours such as hang-ups in grain silos and protection of buried conduits from imposed surface loads. Classical arching models have been extended to consider analysis of backfill as well (e.g. Mitchell et al., 1982; Mitchell, 1992; Li and Aubertin, 2009, and their previous works referenced therein). For practical application, however, all of these models require empirically calibrated values for certain modelling parameters, and such values must be derived from field data. An example of field data that can be used for such purposes is contained in Figure 6.

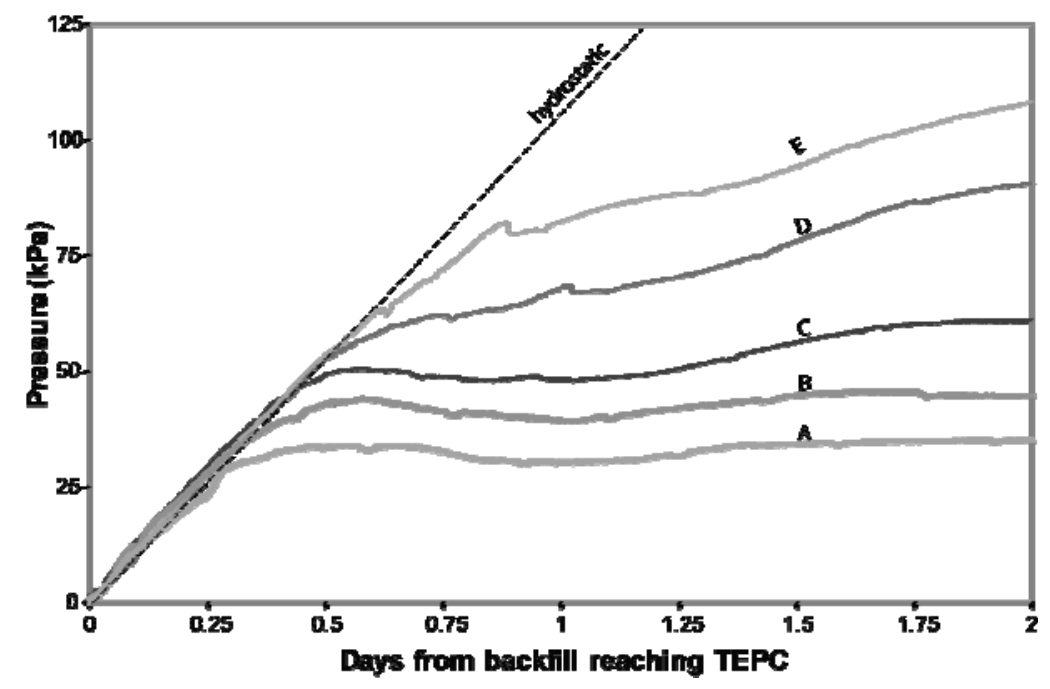

Figure 6 Example horizontal pressure data showing stress reductions towards the fill barricade 
The horizontal pressures acting towards the barricade face are measured at five locations: on the barricade face (set back from the brow approximately $2.5 \mathrm{~m}$ ), at the lower quarter-height point (B) and mid-height point (A); at the brow (C); at a point $3.5 \mathrm{~m}$ from the brow and into the stope (D); and at the stope mid-point (E). It is important to note that, in this example, the pressures generated on the barricade face are generally about half of those exerted at the centre of the stope. Similar results have been obtained for pressure reductions within the drifts for barricades set further back from the brow (Grabinsky et al., 2008).

\subsection{Paste response to dynamic loads}

Many paste fills remain close to saturation (Grabinsky et al., 2005), leading to some concerns about the liquefaction potential of paste fills. As stated by D. Landriault in a keynote address at the 2006 Ninth International Seminar on Paste and Thickened Tailings (Landriault, 2006):

\section{"Paste backfill, because of its perceived potential to liquefy if exposed to seismic activity from localised blasting or rock burst, is never placed underground without at least a low concentration of cement."}

This naturally leads to the question: how low a concentration of cement is sufficient? There is little experimental evidence to guide the engineer in making such a decision. In the 'Handbook on Mine Fill', Henderson et al. (2005) cite heuristics suggested by Aref et al. (1989) recommending 3\% cement and a void ratio of 0.96 or less, and by Been et al. (2002) who found that $1 \%$ cement was required to prevent liquefaction of paste fill at Neves Corvo mine. To these heuristics could be added the result of Clough et al. (1989) who studied the liquefaction potential of cemented sands and suggested a minimum unconfined compressive strength (UCS) of $100 \mathrm{kPa}$. The Clough et al. (1989) heuristic was also investigated for Golden Giant paste tailings by le Roux et al. (2004), who suggested that the $100 \mathrm{kPa}$ recommendation may even be conservative. Some field evidence that may help provide context for these heuristics is presented in Figure 7.

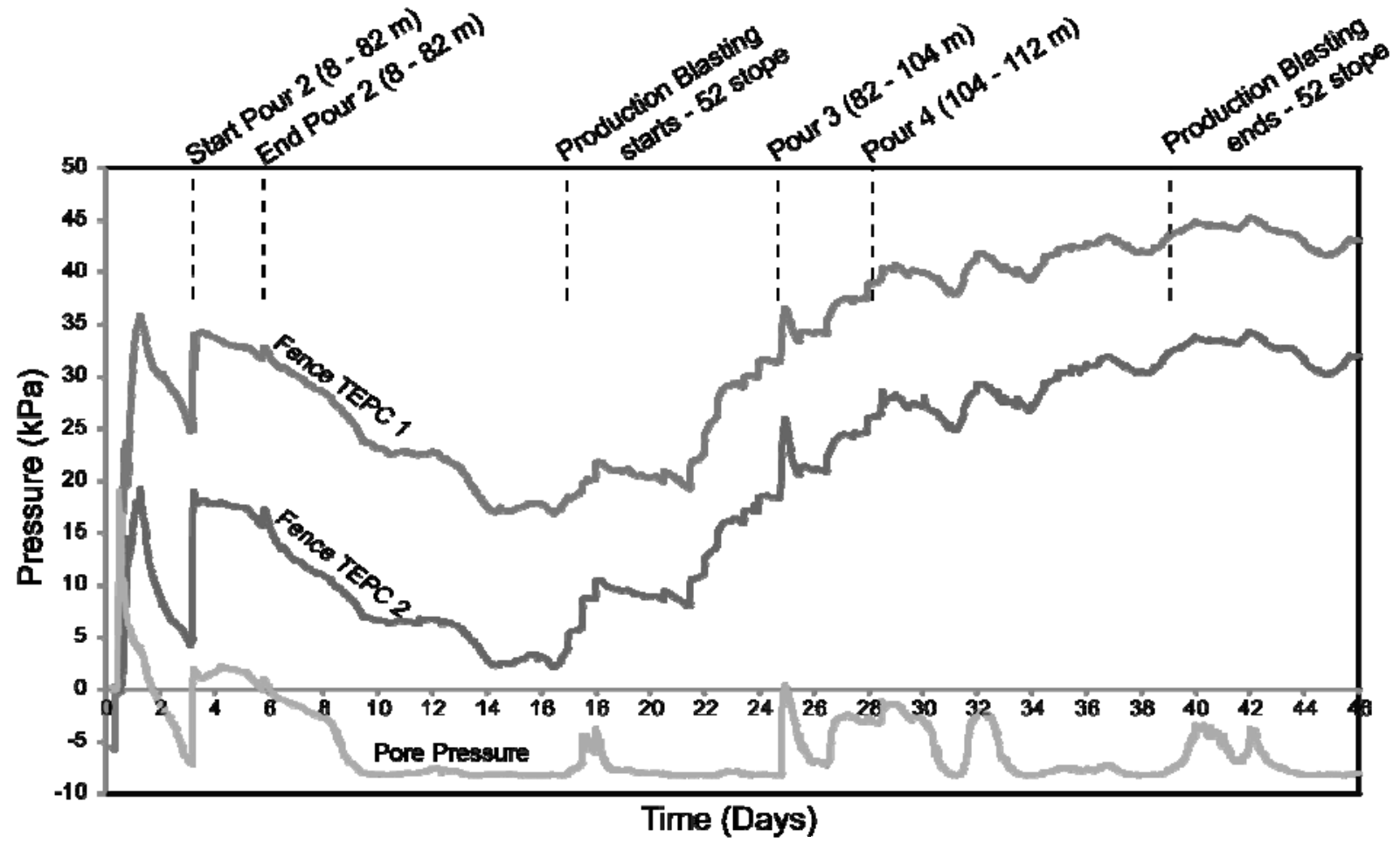

Figure 7 Example response of barricade stresses to production blasting at 17-39 days cure

Figure 7 shows total stress and pore water pressure results immediately behind a fill barricade. Filling commences at day zero and the pour for the plug is completed in about a day. Pore pressures start dissipating after several hours, indicating the onset of hydration. The binder in this case is 3\%, 50:50 NPC:CFA. When plug filling stops, total stresses immediately decrease at a rate consistent with pore pressure dissipation. The second stage of pouring then starts on about day three and lasts for some two days, and it is noteworthy that 
this additional filling changes the pore pressures and total stresses by a commensurate amount, indicating that the effective stresses within the plug are not changed and are therefore effectively shadowed from the remainder of the filling. On day 17 production blasting starts in a nearby stope and continues for some 22 days. At the start of the production blasting sequence the fill fence is approximately 20 to $40 \mathrm{~m}$ from the zones being blasted. The stress changes occurring immediately after the blast (data was recorded every five minutes) are at most a few $\mathrm{kPa}$, and tend to dissipate within several hours. Over longer periods (several days) the stresses do show an upward trend, but this is thought to be due to the overall geometry changes created by the blasting, i.e. static stress transfer as the regional stresses are channelled around the newly opened ground and through the adjacent rock and backfilled zones. Note that the third and fourth stages of the fill were being poured even as production blasting occurred in the adjacent stope, and yet the relatively modest stress changes at the barricade suggest that none of the fill failed in any manner, much less liquefied.

In a more extreme case of dynamic loading, two instrumented stopes were in proximity (about $200 \mathrm{~m}$ ) of a Nuttli Magnitude 3.8 rockburst. The peak particle velocity (PPV) at the stope location is estimated from (Anon, 1997) as between 300 to $350 \mathrm{~mm} / \mathrm{sec}$ for such an event. The backfill was well cured at this point (about half a year), but appears to have survived the event. The instrumentation has largely survived, although some stresses have since gone out of range of the cell's design.

\subsection{Temperature induced stress changes}

It is common practice in the design of civil engineering structures made of steel or reinforced concrete to account for the contraction and expansion that will occur with temperature fluctuations, however, the significance of such a temperature effect for mine backfill has yet to be investigated or demonstrated. At one of the monitored sites, however, the filling was stopped due to operational problems and yet the instrumentation continued to monitor an increase in total stresses which seemed to correlate to increases in temperature, as shown in Figure 8.
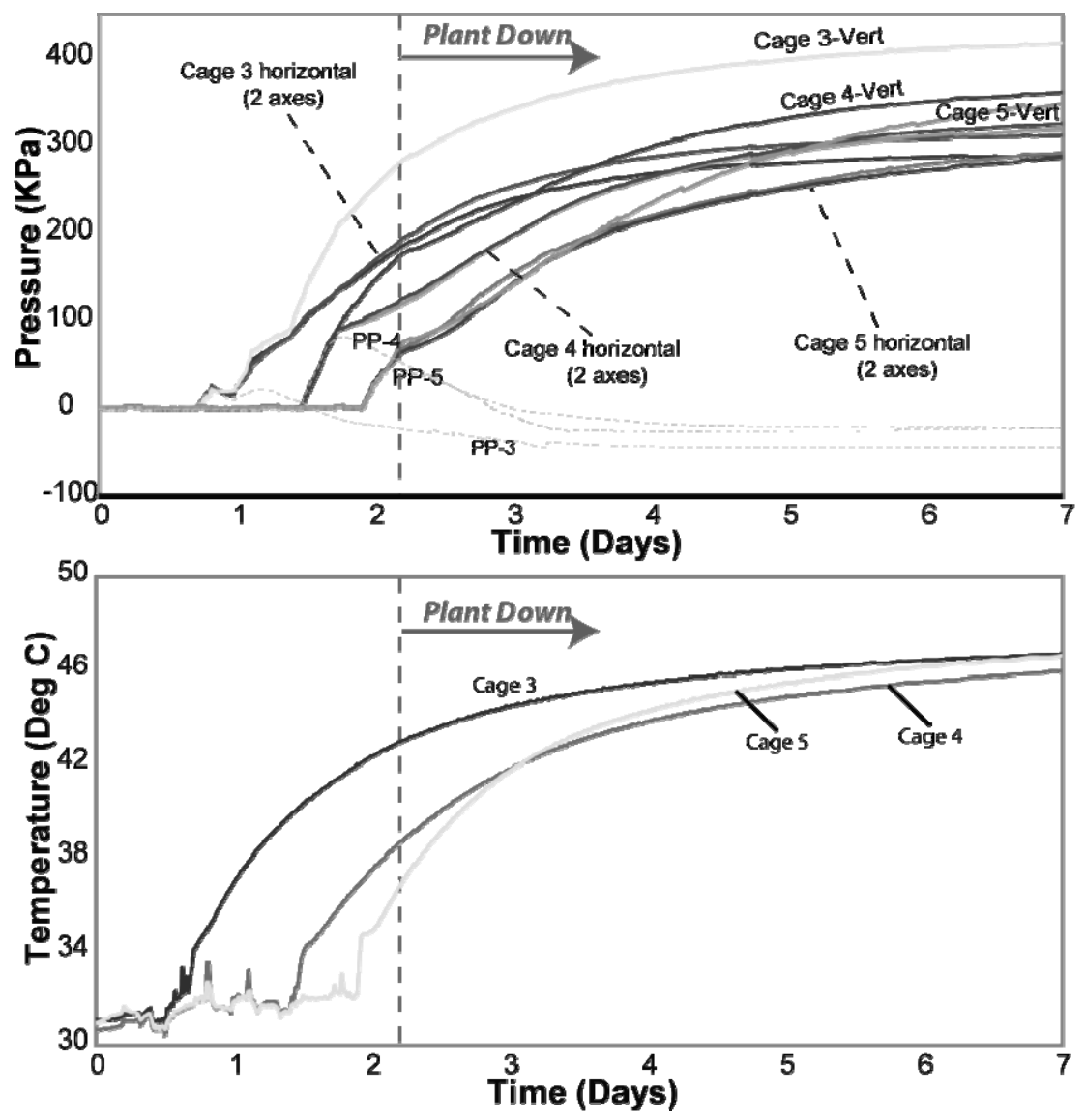

Figure 8 Example of increasing temperature and total stress after filling has stopped 
Temperature effects on total load cells, both in loaded and unloaded conditions are well understood (Daigle and Zhao, 2004) and the instrument supplier provided a calibration for the cells used. Independent tests in the laboratory, in both loaded and unloaded configurations, confirmed that the corrections for these cells should be less than $0.5 \mathrm{kPa} /{ }^{\circ} \mathrm{C}$ (Grabinsky and Thompson, 2009), such that a temperature increase of $16^{\circ} \mathrm{C}$ (i.e. from about $30^{\circ}$ to about $46^{\circ} \mathrm{C}$ ) should result in an over-registration in stress of no more than $8 \mathrm{kPa}$. The stress and temperature changes for cage 4 (i.e. Temp 4 and TEPC4-1,2,3 in Figure 8) are correlated by a factor of about $27 \mathrm{kPa} /{ }^{\circ} \mathrm{C}$ with a coefficient of determination better than 0.99 . The correction factor of $0.5 \mathrm{kPa} /{ }^{\circ} \mathrm{C}$ pales in significance to the observed $27 \mathrm{kPa} /{ }^{\circ} \mathrm{C}$ increase, and it is therefore postulated that the observed stress rise is due to a thermal expansion potential that has been constrained by the surrounding rock mass. The fact that the stress rise effect is virtually identical in the three orthogonal directions, corresponding to the three independent total stress cells, is consistent with the notion of an increase in bulk pressure, assuming the thermal expansion effect is an isotropic one. Further work in both the laboratory and the field remain to better explain this apparent temperature induced stress effect, but in the mean time it should be borne in mind when interpreting the field stress results that temperature effects may play a nontrivial role in the paste's field behaviour.

\subsection{Summary of lessons learned from field studies}

There are some important lessons to be learned from these field studies. First and foremost is that it is possible to carry out extensive field measurement campaigns. The survival rate for the installed instrumentation was up to $95 \%$. The instrumentation is most at risk in weak ground, or in a stope that has been left open for a significant time, thus going beyond a safe stand up time. Horizontally oriented instrumentation lines can be protected by covering with a sand berm and can withstand moderate ground falls. Direct hits to the instrumentation cages and/or their exposed connecting instrumentation lines are more likely to be problematic.

The integrated interpretation of total stress, water pressure (or suction), and temperature yields important insights about when the binder sets and when the backfill's network of solid particles starts to carry effective stress. The development of these stresses within the fill mass, towards the brow, and through the undercut towards the fill barricade can be monitored and the results used to calibrate the various empirical or analytical models available to assess stresses on barricades.

The instrumentation can survive nearby production blasting and even rockbursts with associated PPV's in excess of $300 \mathrm{~mm} / \mathrm{sec}$. The preliminary information gathered by such field monitoring suggests that paste may be far less susceptible to liquefaction than previously thought. Finally, the instrumentation of a stope may provide data that bring to light phenomena previously not considered, or thought to be insignificant, such as the temperature effect discussed in the previous section. As future designs become more rational and highly optimised, the importance of such effects may become more critical.

\section{Instrumentation design}

Selection of individual transducers and their integration into a system must be done carefully to achieve the kinds of results just illustrated. Some general guidelines are provided here, but discussion with instrument suppliers and manufacturers is always warranted when considering a particular mine's monitoring requirements.

\subsection{Individual transducers}

\subsubsection{Total earth pressure cells}

The essential design concept of total earth pressure cells (TEPCs) has been in existence for decades, but recent improvements in manufacturing techniques have enhanced their performance considerably. For example, many of the total stress cells tested by Daigle and Zhao (2004) had temperature correction factors in excess of $5 \mathrm{kPa} /{ }^{\circ} \mathrm{C}$ - an order of magnitude higher than that for the TEPCs used in this research program - and demonstrated a stronger dependency to the magnitude of loading. The TEPCs manufactured for this research work (by RST Instruments, Vancouver) were $225 \mathrm{~mm}$ diameter and approximately $9 \mathrm{~mm}$ thick, providing a high aspect ratio to minimise inclusion affects. 
Vibrating wire (VW) sensor technology was chosen. Within the last few years better signal processing technology has been incorporated into the data acquisition boards for VW sensors and their precision has therefore been extended. When large stress jumps might be anticipated during the mining process, the TEPC range should probably be specified for the upper limit of anticipated pressures, and then the precision checked to see if it remains within acceptable tolerance for the intended application.

The VW sensors contain a thermal data channel to aid in subsequent temperature corrections. This temperature channel can also be used to assess temperature changes in the fill mass arising from binder hydration.

The TEPCs are typically constructed at near-ideal pressure and temperature conditions (when constructed in Vancouver). When they are initially employed underground they will be subjected to the stack effect, or air pressure change relative to sea level. This initial pressure can be double checked against a barometer and ambient temperature transducer, which should be installed in the same housing as the data acquisition system. In geotechnical engineering it is conventional to work in gauge pressures (i.e. relative to atmospheric pressure) and this is true for total stresses as well as water pressures. The initial pressure on the TEPC when installed underground can be removed either by programming within the data logger, or subsequently as a post-processing step.

\subsubsection{Water pressure/suction cells}

Water pressures were measured in this research project using VW-based piezometers. The tips of the piezometers were prepared using boiled water (in an attempt to de-air the water) and were filled underground, thereby essentially removing the initial air pressure effect discussed above. In conventional geotechnical site investigation it is sometimes the case that the tip is filled with a glycol mixture in order to minimise the potential for the tip to desaturate and register an anomalous suction. This may cause difficulty in making the tip re-establish continuity with the ground water. However, this step was not found to be necessary so long as the piezometers did not remain in open ground for more than several days.

As demonstrated in various laboratory studies (Grabinsky and Simms, 2006; Helinski et al., 2007; Simms and Grabinsky, 2009) it is possible for the water pressure to drop below atmospheric pressure, in which case the pressure drops below zero and is defined as a suction. The piezometers employed in this research had tips with an air entry value (AEV) of about $20 \mathrm{kPa}$ - that is, they could register suctions up to about $20 \mathrm{kPa}$ before the tips desaturated and were no longer reliable.

Very large suctions can be generated if the pore sizes are small enough. For the grain sizes typical of mining pastes, suctions of several hundred $\mathrm{kPa}$ (or several 'atmospheres of negative pressure') could theoretically occur. In this research project any suctions that might occur were measured using heat dissipation sensors (HDSs, Campbell Scientific model L229). The HDSs also have an AEV of about $20 \mathrm{kPa}$, but their design is such that the measurement is only meaningful if the AEV is exceeded. Therefore, if the pore water pressures measured by the piezometers fall below zero and become increasingly negative to about $20 \mathrm{kPa}$ suction and subsequently unreliable, then this is the point at which the HDS should start to register a meaningful suction and will take over monitoring the development of even stronger suctions.

While monitoring suctions may be important from a theoretical perspective, the practical implication of strong suctions is that the binder is having great effect and the potential to generate positive pore pressures through loading, for example, is reduced. Therefore it is probably sufficient in routine monitoring to simply use piezometers and disregard their readings once the AEV suction is exceeded, insofar as paste backfill strength is concerned.

\subsubsection{Electromagnetic (EM) transducers}

The ionic changes that occur during hydration can have a marked influence on the bulk electrical conductivity (EC) of the backfill, and therefore monitoring EC changes and correlating these changes with changes in effective stress and temperature can provide a more complete understating of hydration in situ. Another EM parameter that has been used in geotechnical engineering is the dielectric permittivity, which has been correlated with volumetric water content (VWC). Monitoring VWC is potentially of great interest in backfill research. Unfortunately, the dielectric permittivity is indirectly influenced by EC as well as other 
changes that take place during hydration such as decreasing porosity and increasing pore tortuosity. Therefore calibrating VWC against EC alone is not possible.

All of the stopes in the research program employed EM probes built by Decagon Devices Inc., i.e. the $\mathrm{ECH} 2 \mathrm{O}$ probe and the $5 \mathrm{TE}$ probe. The EC data from these probes must be interpreted carefully but when it is integrated with the interpretation of stresses and temperatures the results are compelling. At this point, however, it should be considered strictly a research tool for paste backfill applications.

\subsubsection{Displacement transducers}

The displacement transducers used in the research were relatively inexpensive and robust industrial potentiometers that provided good range and precision for the intended application.

\subsubsection{Other transducers}

Blasting (test blasting as well as production blasting) was monitored for three of the test stopes. This was highly specialised work using high range and highly sensitive triaxial accelerometers, monitored using a high frequency digital recorder. Results from this system are beyond the scope of the current paper. Two different forms of dynamic pore pressure transducers were also attempted with the high frequency digital recorder, but neither gave meaningful results. It is not known if this is because of poor experimental setup, or if the fluid phase of the paste simply never responded to blasting loads. Tilt and compass transducers were also installed in the instrument cages to determine if the cages' orientations drifted during filling, but any such cage movements turned out to be small enough that they could be ignored in the final analysis of results.

\subsection{System integration}

Although the individual transducers were sourced from a variety of manufacturers, it was left up to one manufacturer to build the entire system that would ensure the integrated components worked properly as a whole unit. As previously shown in Figure 2, the various transducers were assembled into cages, with the assumption that the response of the paste would be homogeneous within the sampled volume of the cage. While this is true for practical purposes, the transducers had enough precision to show the small differences between transducers that would occur due to elevation differences. For example, total pressure cells mounted with a relative vertical offset of $0.1 \mathrm{~m}$ would show a pressure difference of $2 \mathrm{kPa}$ for a $20 \mathrm{kN} / \mathrm{m}^{3}$ paste's unit weight (i.e. $20 \mathrm{kN} / \mathrm{m}^{3} \times 0.1 \mathrm{~m}=2 \mathrm{kPa}$ ) while the paste was still fresh during initial filling.

All of the instruments within a cage were connected into a single multi-strand wiring cable with Kevlar core to protect the cables from abrasion and tension during installation. Each wiring cable terminated in a single connector so that each cage was simply connected into the data acquisition unit, thereby avoiding mistaken connections between cages and amongst transducers within a cage. More than once these cables were severed during installation (i.e. by rockfalls, before the practice of protecting the cables in conduit and sand berm was adopted), but because of the wiring methodology it was possible to efficiently repair the system during installation and continue with the monitoring program.

Every stope had to be carefully considered to determine which cages, and other transducers, should be monitored from overcut locations, and which should be monitored from the undercut. It is recommended that wherever possible, cables be installed from the undercut due to the relative ease in protecting the cables.

At one operation, dataloggers were connected to surface via Ethernet. This transformed the instrumentation from a research tool into an operational tool, as the real time fence pressure and displacement data were used to decide whether a pour could be continuous or multi-stage. Networking of data to surface is a recommendation in all further fieldwork of this type. It would only be a technical matter to have such networks accessed from anywhere in the world, which would enable mine personnel and consultants to monitor filling progress regardless of their actual location.

\section{Instrumentation installation}

Every partner mine was ultimately responsible for conceiving and implementing the deployment system for the instrumentation, with input from the research team as required. The main components of concern for the installation included: i) the instrumentation cages within the main stope; ii) the instrumentation cages and/or 
individual instruments mounted in the undercut and immediately behind the fill barricade; iii) the displacement transducer array on the free face of the barricade; and iv) additional instrumentation in boreholes and remote locations in support of the blast monitoring program (not considered here).

Placing instrument cages in the undercut locations was accomplished by mounting the cages on a T-support structure attached to a base block, as previously shown in Figure 3. The system was assembled in a safe location in the undercut and then moved by remote control LHD vehicle to a position in proximity of the brow. Video cameras mounted on these recorded visual evidence of the filling process, which provided additional assurance that the paste actually flowed through the wire mesh of the cages and completely encapsulated the transducers contained within them (Figure 9).
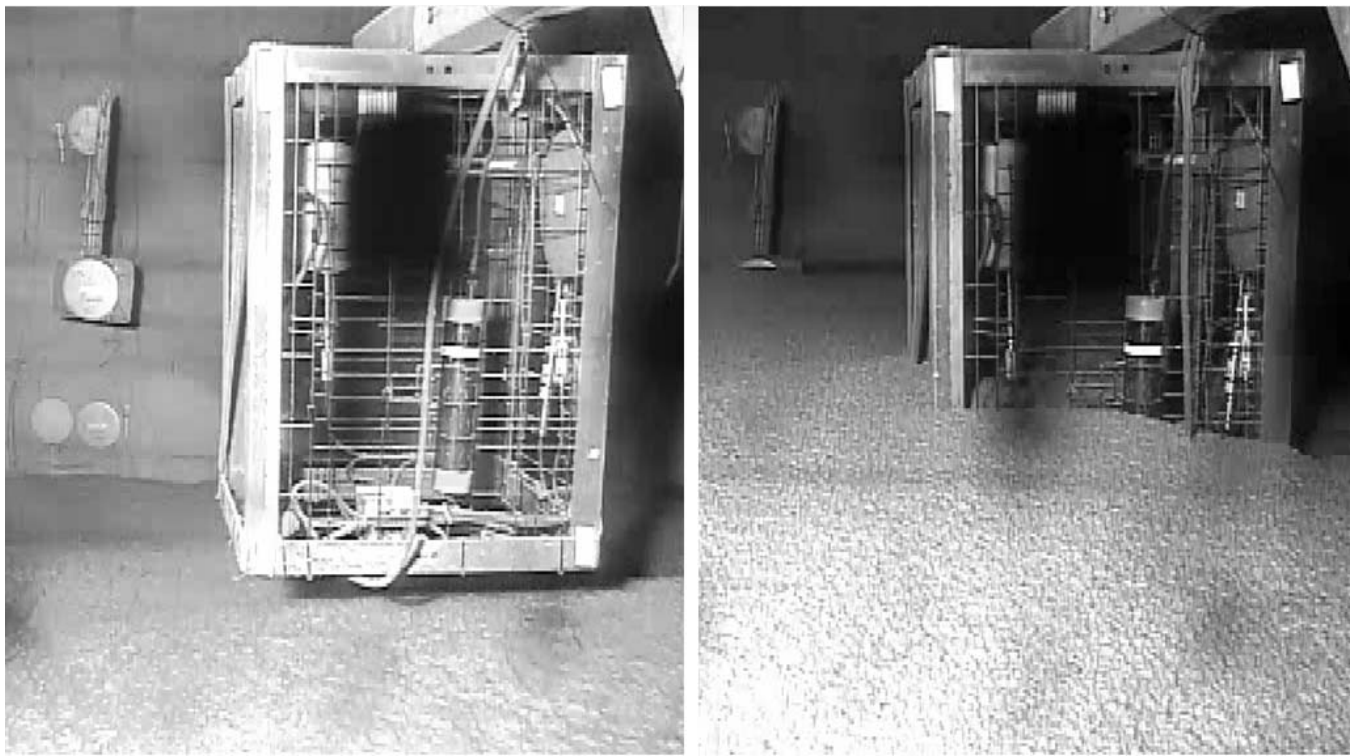

\section{Figure 9 Example of paste flowing through the instrument cage's mesh}

Figure 9 also shows (in the background) total stress cells mounted directly against the fill barricade. The mounting method depended on the barricade's construction details, but the techniques generally worked well so long as the cell remained within a few centimetres of the barricade's back surface. One attempt was made at mounting a cell on a strut that protruded from the wall, in order to capture stresses a metre or more behind the wall, but this does not work well because the strut inherently ties the displacements in vicinity of the cell to the wall displacements thereby making interpretation of the stress results difficult. A better method for measuring stresses within a few metres of the barricade is to suspend the cells on flexible supports, as shown in Figure 10.

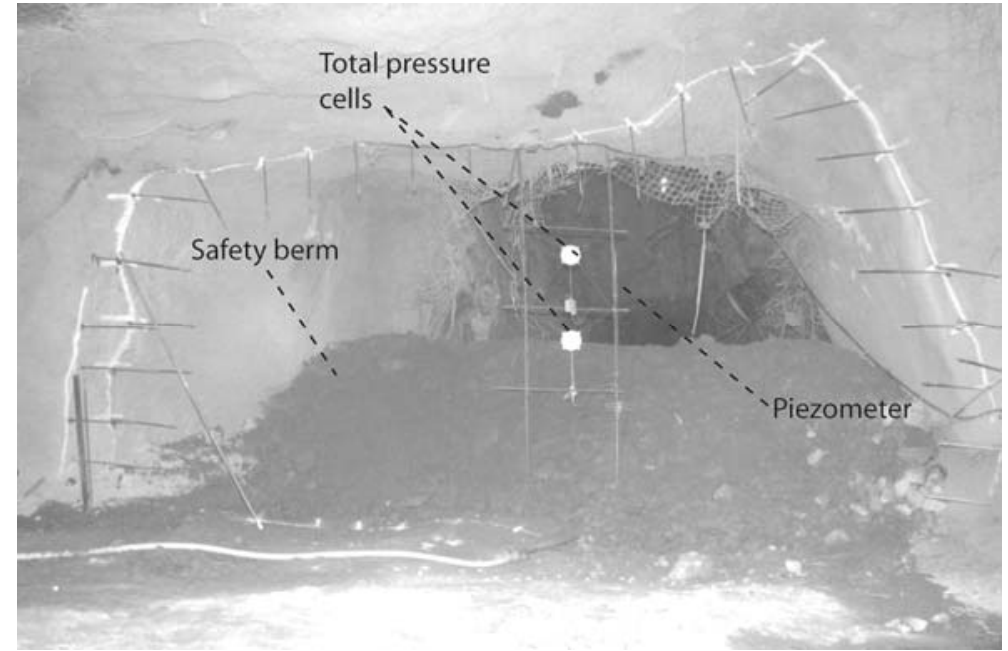

Figure 10 Example of instrumentation mounted about a metre behind the barricade 
A base block and cable system was found to be suitable for suspending the cages throughout the height of the stope, as previously shown in Figure 3. Generally a pulley system was suspended from the overcut prior to blasting the stope, with the details of this system being carefully considered to avoid damage during production blasting. A combination of winches and tuggers were then used to either pull cages up from the undercut, or lower cages down from the overcut.

At every stope the free face of the barricade was monitored for displacements using an array of displacement potentiometers, as shown in Figure 11. During stope filling the host rock to which this frame is attached is virtually motionless, so that the frame itself does not deform and affect the measured displacements. This might not be true for subsequent adjacent mining, but by this point the barricade stability is typically no longer an issue and the barricade may even have been removed to facilitate the next stage of mining.

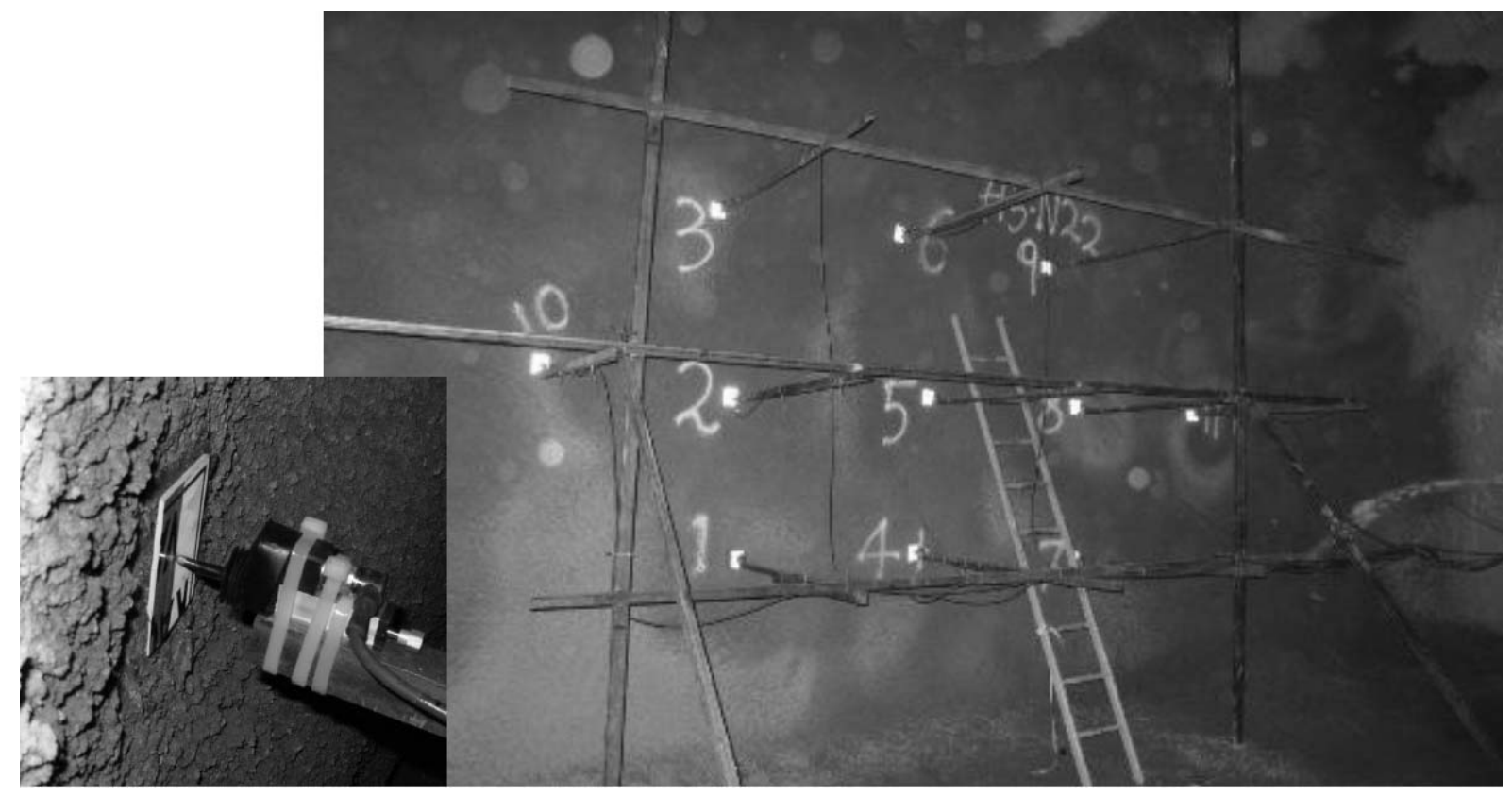

Figure 11 Example of displacement array mounted near free face of barricade. Inset: displacement transducer attached to the frame, with sensing rod bearing on a plate embedded in the shotcrete

\section{Ongoing research in support of routine design}

At the outset of this research project each mine expressed concern about the potential impact the instrument installation activities could have on their production schedules. With careful planning it was possible to integrate the various research related activities within the production schedule, such that the stope cycle time was not extended by more than a few days. This could further be optimised so that routine monitoring would not delay construction at all. However, instrumentation installation did require extra human resources from the mine, and the cost of the consumable instrumentation was nontrivial (generally in excess of C\$100,000). While the scope of this instrumentation was necessary for the research program, it would not be practical or even necessary on a routine production basis for a mine and a simplified instrumentation strategy is seen as a future research and development objective.

The research results to date suggest that some form of ongoing monitoring strategy should be incorporated into the QA/QC procedures for every mine. The details of such a strategy would depend on many factors, such as variability of geomechanical conditions within the mine, the stage of mining, and the level of design optimisation that the mine is trying to achieve. However, whatever monitoring program is undertaken, it would be desirable that: i) the instrumentation be robust and easy to install; ii) the installation be monitored remotely to avoid having personnel at the barricade during filling; and iii) the mine's engineering team who interpret the instrumentation output be familiar with the form of expected monitoring results and determine alert levels and follow up procedures so that the team reacts appropriately when the unexpected is encountered. 
Within the scope of the current research program, extensive laboratory testing is underway to help develop calibrated models that appropriately back-analyse the results obtained from the field experiments. Once confidence in the modelling approach is obtained, better predictive analyses can be carried out to consider the consequences of changes to a given mine's current operating procedures. For any changes being contemplated by the mine, ongoing instrumentation can then be used to verify and ground truth the behaviour predicted by the models. Future research will focus on developing practical instrumentation techniques to help the mines in their ongoing assessment of current and planned backfilling strategies.

\section{Conclusions}

Geomechanical mine design practices have traditionally been characterised by limited input data, complex material behaviour, and new design parameters for each 'unit' (i.e. stope) produced. This necessitates a specialised engineering approach, one which relies heavily on experience but is guided by fundamental practical science. Where confident predictions of system behaviour cannot be made, an "observational" approach to design must be used.

The geomechanical design of cemented paste backfill systems has for too long relied on empiricism. When purely empirical design techniques are employed it is difficult to quantify just how safely (or unsafely) an existing system is performing. Further, it becomes tenuous to predict the behaviour of systems with characteristics differing from those of systems within the experiential database. To progress towards a more rational engineering approach we need data on the actual field performance of the system being considered.

A comprehensive instrumentation strategy for researching the geomechanical behaviour of cemented paste backfill systems has been developed and implemented at five stopes in three different operating mines. Although this system is necessarily complex given the fundamental nature of the research being undertaken, it has been shown that the system is capable of reliably producing high quality data that provides important insights into the operating behaviour of the backfill system for the particular stope being studied. For some of the participating mines the research results have already led to changes in standard operating procedures that will yield a very high rate of return on their investment in the research. All of the participating mines have committed to ongoing research and development work and continued monitoring to optimise their backfilling operations.

The collective results of the instrumentation programs, and further interpretation of those results guided by carefully controlled laboratory studies, will help to develop a better understanding of backfill performance in situ. Some of this understanding will be of a general nature and transferrable to other mining operations. In most cases, however, mining operations should plan for a future in which routine monitoring of some form becomes an integral part of their ongoing engineering strategy to optimise the performance of their paste backfill systems.

\section{Acknowledgements}

The research project described in this paper is a collaborative effort led by Professors M.W. Grabinsky and W.F. Bawden and their Post Doctoral Research Fellow B.D. Thompson at the University of Toronto, with fellow investigators Professors E. Bentz, D. Hooton, B. Mohanty, and K. Xia (University of Toronto), G. Cascante (University of Waterloo) and P. Simms (Carleton University), and their respective graduate students and research assistants.

Technical assistance in the design, development, and deployment of the instrumentation systems was provided by J. Matheson of Hoskin Scientific (Burlington, Ontario) and R. Taylor and D. Polvi (RST Instruments, Vancouver).

A great many personnel at each of the participating mines (Williams, Kidd, and Cayeli) assisted with the conceptualisation and development of the instrumentation deployment systems.

Financial support for the project was provided by Barrick Gold Corporation, Inmet Mining Corporation, and Xstrata Copper Canada, as well as by the Natural Sciences and Engineering Research Council Canada (NSERC). 


\section{References}

Acker, P. (2004) Swelling, shrinkage and creep: a mechanical approach to cement hydration, Materials and Structures: Concrete Science and Engineering, 37, pp. 237-243.

Anon (1997) Rockburst Research Handbook: Canadian Rockburst Research Program 1990-1995, CAMIRO Mining Division, Sudbury, 3 Vol.

Aref, K., Hassani, F.P. and Churcher, D. (1989) A study on liquefaction potential of paste backfill, In Proceedings 4th International Symposium on Mining with Backfill, Montreal, pp. 405-415.

Been, K., Brown, E.T. and Hepworth, N. (2002) Liquefaction potential of paste fill at Neves Corvo Mine, Portugal, Transactions of the Institution of Mining and Metallurgy, April 2002, pp. A47-A58.

Clough, G.W., Iwabuchi, J., Rad, N.S. and Kuppusamy, T. (1989) Influence of cementation on liquefaction of sands, Journal of Geotechnical Engineering, Vol. 115(8), pp. 1102-1117.

Daigle, L. and Zhao, J.Q. (2004) The influence of temperature on earth pressure cell readings, Canadian Geotechnical Journal, Vol. 41(3), pp. 551-559.

Grabinsky, M.W., Simms, P., Bawden, W.F. and le Roux, K. (2005) In situ properties of cemented paste backfill and implications for mine design, in Proceedings of Symposium on Mines and the Environment 2005, RouynNoranda, pp. 157-167.

Grabinsky, M.W. and Simms, P. (2006) Self-desiccation of cemented paste backfill and implications for mine design, in Proceedings Ninth International Seminar on Paste and Thickened Tailings, R. Jewell, S. Lawson, P. Newman (eds), Australian Centre for Geomechanics, Perth, Australia, pp. 323-332.

Grabinsky, M.W., Bawden, W.F. and Thompson, B. (2008) Back-analysis of barricade performance for a paste filled stope, in Proceedings Symposium on Mines and the Environment 2008, Rouyn-Noranda, pp. 162-174.

Grabinsky, M.W. and Thompson, B.D. (2009) Thermally induced stresses in cemented paste backfill, Geotechnical News, Vol. 27(3), pp. 36-40.

Helinski, M., Norris, P., Fourie, A. and Fahey, M. (2008) Preliminary results from an investigation into the effect of application of effective stress to cemented paste backfill during curing, Australian Centre for Geomechanics Newsletter, Vol. 31, pp. 10-13.

Helinski, M., Fourie, A., Fahey, M. and Ismail, M. (2007) Assessment of the self-desiccation process in cemented mine backfills, Canadian Geotechnical Journal, Vol. 44, pp. 1148-1156.

Henderson, A., Revell, M.B., Landriault, D. and Coxon, J. (2005) Chapter 6: Paste Fill, In Handbook on Mine Fill, Y. Potvin, E. Thomas and A. Fourie (eds), Australian Centre for Geomechanics, Perth, Australia, 178 p.

Landriault, D. (2006) Keynote Address: They said "It will never work" - 25 years of paste backfill 1981-2006, in Proceedings Ninth International Seminar on Paste and Thickened Tailings, R. Jewell, S. Lawson, P. Newman (eds), Australian Centre for Geomechanics, Perth, Australia, pp. 277-292.

le Roux, K., Bawden, W.F. and Grabinsky, M.W. (2004) Liquefaction analysis of early age cemented paste backfill, in Proceedings Eighth International Symposium on Mining with Backfill, Beijing, pp. 233-241.

Li, L. and Aubertin, M. (2009) Influence of water pressure on the stress state in stopes with cohesionless backfill, Geotechnical and Geological Engineering, Vol. 27, pp. 1-11.

Mitchell, R.J., Olsen, R.S. and Smith, J.D. (1982) Model studies on cemented tailings used in mine backfill, Canadian Geotechnical Journal, Vol. 19(3), pp. 289-295.

Mitchell, R.J. (1992) Centrifuge model studies of fill pressures on temporary bulkheads, Canadian Institute of Mining Bulletin, Vol. 85(960), pp. 48-54.

Simms, P. and Grabinsky, M.W. (2009) Direct measurement of matric suction in triaxial tests on early age cemented paste backfill, Canadian Geotechnical Journal, Vol. 46, pp. 93-101.

Yilmaz, E., Benzaazoua, M., Belem, T. and Bussière, B. (2009) Effect of curing under pressure on compressive strength development of cemented paste backfill, Materials Engineering, Vol. 22, pp. 772-785. 